\title{
Methodology for the metaphysics of pregnancy
}

\author{
Suki Finn ${ }^{1}$ (D)
}

Received: 12 June 2020 / Accepted: 10 May 2021/Published online: 16 July 2021

(c) Crown 2021

\begin{abstract}
One of the central questions in the metaphysics of pregnancy is this: Is the foetus a part of the mother? In this paper I aim not to answer this question, but rather to raise methodological concerns regarding how to approach answering it. I will outline how various areas attempt to answer whether the foetus is a part of the mother so as to demonstrate the methodological problems that each faces. My positive suggestion will be to adopt a method of reflective equilibrium. The aim of this is to ensure that pregnancy be included in the tribunal of experience that our theories are held up against such that our theories can accommodate what we say about pregnancy, whilst also ensuring that what we say about pregnancy be theoretically informed. That way, we rethink pregnancy in light of our theories as well as rethinking our theories in light of pregnancy.
\end{abstract}

Keywords Methodology $\cdot$ Metaphysics $\cdot$ Pregnancy $\cdot$ Reflective equilibrium

\section{Introduction: the question}

Recently, there has been some debate over whether the foetus is a part of the pregnant mother. ${ }^{1}$ This metaphysical question about pregnancy is of great importance, not only to pregnant metaphysicians, but to all of us, given that we are all the result

\footnotetext{
1 Most relevantly for this paper, see Kingma (2019) and Smith and Brogaard (2003). Though I note (thanks to an anonymous reviewer) that the ontology of pregnancy has been investigated from various other perspectives, both indirectly in dealing with the individuation of embryos (e.g. Nuño de la Rosa, 2010) and life cycles (e.g. DiFrisco \& Mossio, 2020), and also directly when examining pregnancy
}

This article belongs to the Topical Collection: EPSA2019: Selected papers from the biennial conference in Geneva

Guest Editors: Anouk Barberousse, Richard Dawid, Marcel Weber

Suki Finn

suki.finn@rhul.ac.uk

1 Royal Holloway, University of London, Egham Hill, Egham, Surrey TW20 0EX,

United Kingdom 
of a pregnancy. So, were you a part of your mother (or whoever gestated you) ${ }^{2}$ ? How do we go about finding an answer? Can the answer be found within metaphysics itself? Is an empirical study of the biological sciences required? Is there an answer to the question that reflects some objective truth of the matter? These are all separate questions that I do not promise to answer but rather to explore. To do so, in this paper (and others), I focus on Elselijn Kingma's metaphysical approach to pregnancy, who makes the following methodological remark:

I have, throughout this essay, assumed what strikes me as a plausible view: that whether or not something is part of an organism-which I take to be a metaphysical fact-is not determined by social or psychological facts. But this assumption could be challenged. ${ }^{3}$

Indeed, in challenging that assumption, our question about the foetal-gestator relationship may not be something that admits of deep metaphysical answers and "might well be taken to cast doubt on the assumption that a single, non-context dependent answer to our question can be given."4 Kingma notes that if we were to drop such assumptions, then investigating pregnancy from within metaphysics (or empirically informed philosophy of biology) will not "come close to settling [the question]" 5 So how will we get closer to answering our question? Should we grant Kingma's assumption? How should we navigate the interplay between received philosophical theory and new evidence on pregnancy? It is to these methodological, more meta-philosophical, issues that I turn to in this paper.

The metaphysics of pregnancy fits quite nicely into the domain that Katherine Hawley calls 'applied metaphysics'. On her construal, applied metaphysics concerns "metaphysical issues which lend themselves to application beyond philosophy [and] are often (though not always) issues to do with categorising, classifying and organising the world." ${ }^{6}$ Pregnancy is clearly a topic that applies outside of philosophy: many of us have been, will be, or are pregnant, and (as I noted at the start) all of us are the result of a pregnancy. And this paper aims to show how a philosophical inquiry of pregnancy will help to categorise, classify, and organise the entities

\footnotetext{
Footnote 1 (continued)

from a relational perspective (e.g. Howes, 2008) and from the perspective of biological individuality and organismality (e.g. Grose, 2020 \& Nuño de la Rosa et al., 2021). All these endeavours are affected by the same kinds of methodological issues that I address here, namely how our philosophical theories relate to the empirical facts as delivered by current sciences. As such, much of what I say here will apply to all of these debates. Yet, due to limitations of space and in order to be consistent with the framework I have published in elsewhere, I will focus on Kingma's approach.

2 From hereon I use the term 'gestator' instead of 'mother' in order to avoid issues of gender and motherhood. Pregnancy is a gendered issue. But not all who are pregnant identify as mothers. As such, 'gestator' is a more inclusive term. Furthermore, 'gestator' allows for a wider scope of pregnant placental mammals rather than just humans, as Kingma's project aims to capture.

3 Kingma (2019) p636. E.g. One might think social facts are metaphysical.

4 Ibid.

5 Ibid.

6 Hawley (2016) p1.
} 
involved in a pregnancy. The sciences also contribute to our general understanding of pregnancy, biology being especially relevant. ${ }^{7}$ But as Hawley notes, "it's not always clear where-or even whether-to draw the boundary between metaphysical questions and scientific questions," 8 and the topic of pregnancy certainly seems to straddle that divide, and necessarily so, too. It is this dance between the philosophical and the empirical that this paper shines a light on, with respect to the case study of pregnancy.

\section{The answers}

So, is the foetus a part of the gestator? This can be answered with a 'yes' or a 'no' (although the options are more varied than that). ${ }^{9}$ I first outline the 'yes' (Parthood) and 'no' (Containment) positions, then I will outline two underexplored views which I have named 'Overlap' and 'Underlap'. Whilst I will not argue for or against the plausibility of any of these views, I present them in order to provide a more thorough framework for the debate as well as a proposed methodology. The aim, therefore, is to provide a foundational guide for those who come to the debate.

\subsection{The parthood view}

This view is put forward by Kingma "One can start by treating talk of [foetuses] being parts of [gestators] as parallel to talk of, say, kidneys being parts of dogs." 10 The foetus and the gestator are not mereologically separate entities, but are related to each other as a (proper) part is to a whole. So, the gestator is the whole, and this gestator has many parts, like limbs and organs, where the foetus is simply one of (albeit a potentially very different and special one of) those parts. It is important to note that this view does not specify what sort of thing the foetus is (e.g. a person or human organism), it only states how it is mereologically related to the gestator - as a proper part.

\footnotetext{
7 Hawley (2006) fn.4 notes that biology may be relevant to metaphysics.

${ }^{8}$ Hawley (2016) p2. This boundary is especially unclear when considering the philosophy of biology or scientific metaphysics. I shall not attempt to delineate or define these entangled areas, but will focus my discussion on the philosophy of biology later. For more on scientific metaphysics (see Soto, 2015).

${ }^{9}$ See Finn (forthcoming) for a taxonomy of the various more complex views. I note (thanks to an anonymous reviewer) that analogous views are considered in other metaphysical discussions of biological phenomena such as holobionts (see e.g. Triviño \& Suárez, 2020), and that a pluralist approach may be appropriate whereby there is more than one correct answer to the question of a foetal-gestator relationship (see e.g. Nuño de la Rosa et al., 2021).

10 Kingma (2019) p612.
} 


\subsection{The containment view}

This view can be seen as the opposite of the Parthood view According to the Containment view, the gestator is literally, and merely ${ }^{11}$, a container for the foetus. Unlike on the Parthood view, here the gestator and foetus are mereologically separate entities. Smith and Brogaard appear to hold this view, and provide the analogy of the foetus being inside the gestator in the same way as "a tub of yogurt is inside your refrigerator" 12 , where the yoghurt is not also a part of the refrigerator. Again, importantly, the Containment view does not state what sort of thing the foetus is, it only says that the foetus is inside the gestator without also being a part of the gestator.

\subsection{The overlap view}

This is an under-considered view where the foetus and gestator share parts (i.e., they overlap) When the overlap is between proper parts, this view holds that there are two entities, the foetus and gestator, which overlap somewhere (but not everywhere, for either entity), and as such share a proper part (rather than an improper part which may include the entirety of one of the entities). If the overlap is improper where the entirety of the foetus overlaps some of the gestator, we are left with a view that is mereologically equivalent to the Parthood view. But it is otherwise not equivalent, and Kingma's analysis is not sensitive to this distinction. In arguing against the Containment view, she does not thereby argue in favour solely of the Parthood view, since the Overlap view is also an option. Note that this Overlap view also does not commit to what type of entity the foetus is nor what parts it shares with the gestator.

\subsection{The underlap view}

This is another under-considered view according to which the gestator is the minimal underlap (or mereological sum) of a container and the foetus, where the container is identified as the maximal remainder of the gestator minus the foetus. Kingma mentions this view only briefly in a footnote:

One might think there are further options: for example, that the pregnant organism and fetus compose a third, larger entity. But this is not a further option; it is a version of the containment view. (Or, if it can't survive the challenge that the larger entity is in fact the pregnant organism, then it is a version of the parthood view. $)^{13}$

\footnotetext{
11 By 'merely', I do not mean that the gestator plays no other role. Rather I use it to draw attention to the notion of 'containment' in the Containment view ruling out a parthood relationship (since on the Parthood view there is still some containment as the foetus is inside the gestator, but it is not 'mere' containment since there exists a parthood relationship too). For an account of the interplay between containment and parthood, see Finn (forthcoming).

12 Smith and Brogaard (2003) p74.

13 Kingma (2019) p610 footnote 3.
} 
Yet Kingma is wrong to think that this is 'not a further option' There is an important distinction between it and the Container view, as the Container view treats the gestator as being merely a container for the foetus. But when we take the mereological sum of the gestator and the foetus, we are left with an entity (the underlap) that is unspecified as a particular thing itself. The Container view may identify the underlapping entity as an arbitrary mereological sum rather than the gestator, whereas the Underlap view identifies that entity as the gestator itself. And when the gestator is the underlap, the gestator will have a proper part that is the foetus, which makes the Underlap view a type of hybrid view where there is both 'mere' containment and proper parthood going on. Here, a container merely contains the foetus, and both that container and the foetus being contained are proper parts of the gestator. So, the foetus being merely contained by something else does not automatically result in a version of the Container view, as this Underlap view displays.

There is also an important difference between the Underlap view and the Parthood view which Kingma does not see, which is due to the identification of entities. On the Parthood view, when we abstract away the foetus part from the gestator whole, we are left with a gestator missing one of its parts. Whereas, on the Underlap view, we are left with a container for the foetus. This is because what is regarded as the 'remainder' on the Parthood view is not identified as an entity in itself, whereas the 'container' on the Underlap view is identified as an entity. Given this distinction then, arguing for a parthood relationship between foetus and gestator (as Kingma does) does not automatically argue in favour solely of the Parthood view, since the Underlap view also allows for a parthood relationship between foetus and gestator. As such, further work needs to be done to motivate the Parthood view over the Underlap view, or else the Underlap view remains a distinct plausible option. ${ }^{14}$

\section{Methodology}

Now that we have a more complete set of answers as to whether the foetus is a part of the gestator, how are we meant to find out which view(s) is/are correct, or which best to adopt? Generally speaking, when asked if $\mathrm{y}$ is a part of $\mathrm{z}$, we could look to $\mathrm{z}$ in order to see if it includes $\mathrm{y}$ as one of its parts. Call this a 'top-down' approach of decomposition: by starting with the whole (at a higher mereological level), we can decompose it into its parts (at a lower mereological level), to see what its parts are. In the case of pregnancy, $\mathrm{z}$ is the gestator, and we are questioning if it has $\mathrm{y}, \mathrm{a}$ foetus, as a part. But the problem is what we should take the whole of the gestator to be, since this is precisely what is at issue here. Indeed, what the gestator is and

\footnotetext{
14 Given Kingma's rejection of 'maximality' (as I discuss in Metaphysics), she cannot use maximality to object to Underlap in favour of Parthood. If the number of entities being a part of entities of the same kind in the Underlap view is unacceptable, then similar reasons apply against the Parthood view.
} 
what they include is the question we are asking, and so the worry is that a top-down approach presupposes the identity of the whole, $\mathrm{z}$, in order to identify its parts - this would be question begging.

Alternatively, a 'bottom-up' approach ascertains whether $\mathrm{x}$ and $\mathrm{y}$ are parts of $\mathrm{z}$ via composition. It considers the mereological sum of $\mathrm{x}$ and $\mathrm{y}$ to see if it (partially or completely) composes $\mathrm{z}$. If so, then $\mathrm{x}$ and $\mathrm{y}$ are parts of $\mathrm{z}$. This bottom-up approach would ask us to find conditions on what it takes to be a unified thing, rather than part of a thing. At first sight then, this may seem to avoid the question-begging presuppositions that we saw in the top-down approach. However, we run into similar problems in assessing whether $\mathrm{x}$ and $\mathrm{y}$ compose $\mathrm{z}$ by having a pre-made idea of what $\mathrm{z}$ is (and thus what its parts are). Instead we must find a way to answer whether the foetus $-\mathrm{y}-$ is part of the gestator $-\mathrm{z}-$ by looking to independent grounds for what the whole $\mathrm{z}$ is, and whether it includes $\mathrm{y}$, the foetus, as one of its proper parts.

So, from where should we begin our investigation into whether the foetus is part of the gestator - is a bottom-up approach more promising than a top-down approach? And how can we adjudicate between the views without presupposing an answer to our question? Specifically, what can count as evidence or data for or against these seemingly competing views? As a first step, I think that clarifying what the aim of the question is will help to determine the methodology. Namely, whether the purpose of the question is to understand which metaphysical view either most accurately describes what we already take pregnancy to be like or best prescribes how we ought to understand pregnancy.

In general, if investigating which theory best fits the world, you start with the backdrop of the world as evidence, and test the theories against it in order to find a match. Thus, the theory is in question and the world gives the answer, such that theories are, crudely, in the business of describing the world. As such, with regard to pregnancy, say that we hold the following as evidence for whether the foetus is a part of the gestator or not: the way we speak of gestators; how gestators feel, see, and think of themselves; how gestators are treated in law, society, and in medical practice, for example. We would then look to see which view of pregnancy fits best with these bits of evidence, in order to capture and clarify what we take pregnancy to be like.

On the other hand, if investigating what the world is like (or ought to be like), you look to theories for guidance. As such, the world is in question (or is up-for-grabs, if you like), and the theories give answers, so that the theories are prescribing the world. With regard to pregnancy, then, the evidence base for finding out whether the foetus is a part of the gestator or not would come from our most successful theories - whatever those theories predict is the case would be what we ought to take as the case. We therefore would learn about and perhaps change our metaphysical view of pregnancy as a result of theorising.

Here we see the emergence of a much-contested issue ${ }^{15}$ as to the relationship between theory and world: sometimes theories tell us what the world is like (or what

15 There are related core problems in the philosophy of science, namely the nature of scientific truth and how empirical facts relate to scientific theories (see e.g. Psillos, 1999 \& van Fraasen, 1980). Further- 
we ought to say it is like), but also sometimes the world tells us which theory is correct (or which theory is best to adopt). This can lead to a self-justifying feedback loop if the very same bits of the world that are under investigation by a theory are used as data to construct that very same theory. Though things are, of course, much more complicated than this binary I present. Often it is argued that looking to the world is never not theory-laden, and as such theory and data are always intertwined. ${ }^{16}$ Yet the way this debate has been set up makes it unclear how to navigate the theory-world relationship here: whether we are to learn from theory about pregnancy, or learn from pregnancy about theory; and which theories in which domains are relevant. For now, I will look only to parts of metaphysics and philosophy of biology.

\section{Metaphysics}

Given that the question of whether the foetus is part of the gestator has been branded by Kingma as an issue in the metaphysics of pregnancy ${ }^{17}$, perhaps metaphysics is a good place to start in order to find an answer. And given the parthood relationship in question, perhaps mereology can shed some light on the issue. Specifically, maximality provides limitations on what can be a part of what, where the term 'maximal' is applied to entities $\mathrm{F}$ that abide by a condition like:

Proper parts of an F are not themselves Fs. ${ }^{18}$

The result of this is that if we take the foetus and the gestator to both be of the same kind ' $F$ ' (say, human organisms), then the foetus cannot be considered to be a part of the gestator. ${ }^{19}$

But an undogmatic approach invites us to consider the status of maximality and how much credence to place in it. How should we weigh up, say, (i) our conviction in maximality, against (ii) our conviction of the parthood relationship between two

\footnotetext{
Footnote 15 (continued)

more (thanks to an anonymous reviewer) it is important to note that scientific metaphysics is increasingly dissatisfied with abstract appeals to what 'theory' tells us about reality. The classic appeals to our best scientific theories (e.g. quantum mechanics or evolutionary theory) have not led to consensus about any metaphysical debates about their interpretation (e.g. objective collapse in physics or species as individuals in biology). Some philosophers have also critiqued the prioritization placed on theory in the first place and pointed us toward experiments and other scientific practices (see e.g. Hacking, 1983). Others have argued for a pragmatic understanding of metaphysics against the idea that our most basic concepts can be defined in separation from our aims in the world (see e.g. Woodward, 2003 \& Mitchell, 1997). As such, there is much debate around these issues, which I cannot do justice to here.

16 E.g., see Kuhn (1977); Popper (1959); Feyerabend (1959); Azzouni (2004).

17 After all, Kingma's (2018) paper is titled 'Lady Parts: The Metaphysics of Pregnancy', and her (2019) paper is titled 'Were you a part of your mother? The Metaphysics of Pregnancy'. This implies at least that the question of the foetal-gestator relationship is metaphysical, and so perhaps a metaphysical methodology is required in order to get an appropriate metaphysical answer.

18 Sider (2001) p1: "Large parts of an F are not themselves Fs". 'Maximality' is used in many ways and this principle is also called an 'exclusion principle'.

19 This is a big 'if'. Maximality alone does not determine any relationship between the foetus and gestator - it must be combined with a commitment to the foetus and gestator being the same kind of thing. See Finn (forthcoming).
} 
human organisms such as the foetus and gestator? If we find that our best metaphysical theories or principles, like maximality, entail that the Parthood view of pregnancy is wrong, then should we give up on that view in favour of another, like the Containment view? Or, as Kingma goes on to suggest, ${ }^{20}$ should we give up on a metaphysical theory or principle, like maximality, if it cannot accommodate for our best account of pregnancy, where that best account may involve a parthood relation between entities of the same kind, F? In other words, what justifies maximality, and could pregnancy be used as a counterexample to it?

The metaphysical literature has historically tended to fall silent on the example of pregnancy. ${ }^{21}$ Given how metaphysics has developed without much consideration of pregnancy, it looks like our metaphysical theories have evolved against a tribunal of experience that did not include pregnancy. So, ought we now (as Kingma suggests) ${ }^{22}$ take pregnancy seriously, only accepting metaphysical theories that accommodate our understanding of pregnancy? But this is easier said than done, and it cannot be done in isolation since our understanding of pregnancy is incomplete. Thus, we see the question arise: what role should pregnancy play in determining our metaphysics, and what role should metaphysics play in determining our view of pregnancy?

Kingma suggests that maximality had been "formed without bearing the possibility of pregnancy in mind" 23 , and as such we should not turn to it, or to other metaphysical theories or principles, to answer whether the foetus is part of the gestator. Instead, she suggests that we revise our commitment to maximality and other metaphysical theories and principles in light of what we know (or our best understanding of) pregnancy:

We should begin our investigation of the metaphysics of pregnancy by looking at pregnancy on its own terms, and not by importing a set of prior philosophical commitments that were formed without bearing the possibility of pregnancy in mind. If those other commitments need revision because pregnancy raises metaphysical difficulties, then so be it. ${ }^{24}$

Indeed, we should not evaluate a topic from a place that has not developed with the topic in mind. Especially when there may be biases and assumptions about that topic already built into the machinery! But, the problem is, we do not have an answer about what we take pregnancy to be like, as this is precisely our question that we are investigating. So how are we to know whether to revise our metaphysics in light of pregnancy, when we do not yet know whether we have a case of a human foetus being a part of a human gestator, for example? Without such information about pregnancy, we cannot use it as a knock-down argument against a theory that

\footnotetext{
${ }^{20}$ See Kingma (2019) p617-618. Note, without maximality, one cannot appeal to too many things of kind $F$ ' in the Underlap view in favor of Parthood view.

21 This may be because historically those who were involved in metaphysics were not those who were involved in pregnancy (specifically, they either could not be pregnant, and those who could disproportionately had not been).

22 See Kingma (2019) p617-618.

23 Kingma (2019) p618.

24 Ibid.
} 
cannot accommodate for it. In order to take pregnancy seriously, 'on its own terms', we need to know about pregnancy. But we do not - it is, currently, an open question as to whether the foetus is a part of the gestator. And indeed, Kingma herself also cannot take pregnancy 'on its own terms' because it is pregnancy itself that she is investigating. 25

Now there may be other areas of metaphysics (that is, there is far more to metaphysics than maximality alone) that could potentially be applied usefully to pregnancy (for example, work on personal identity and persistence through time and change). I leave it for other(s) work to consider whether there are non-questionbegging principles/theories elsewhere in metaphysics that we may turn to for investigating pregnancy. But if Kingma is right as to metaphysics in general not having properly considered pregnancy and having evolved without pregnancy in mind, then the rationale to look outside of metaphysics (and not just outside of maximality) to conduct the investigation still applies. So, if that is the case, without metaphysics being able to accommodate pregnancy, it must be, curiously, that the metaphysical question about pregnancy cannot be answered from within metaphysics itself. Where, then, is the answer?

\section{Philosophy of biology}

Given that the entities in question here are biological entities, it seems that a promising avenue of investigation to pursue would be within the philosophy of biology. Yet many philosophers of biology have their own account(s) of parthood that may not be captured by the mereologists account of parthood. ${ }^{26}$ A strategy to show that biological parts are not mereological parts is by providing examples of quintessential biological parts that do not abide by the formal characteristics of mereological part (such as being transitive, antisymmetric, and reflexive). Specifically, one could show that the biological parthood relation fails to be (one or more of) transitive, antisymmetric, or reflexive, as such:

(i) A biological subunit of a cell is a part of that cell, but a biological subunit is not a part of the organ(ism) of which that cell is a part.

(ii) The functional subunits of an organism are part of that organism, but no organism is a functional subunit of itself. ${ }^{27}$

\footnotetext{
25 If Kingma knew about the metaphysics of pregnancy sufficiently in order to take it seriously on its own terms and reject theories that don't account for it, there would be nothing to investigate in her project 'Better Understanding the Metaphysics of Pregnancy'. Rather, the project would be more aptly 'Better Applying the Metaphysics of Pregnancy' in order to apply what she already takes to know. In order for there to be something to 'better understand', the thing under investigation needs to be open, and cannot be taken as background data.

26 See Kaiser (2018) for an explicit example of this.

27 These examples are from Rescher (1955) p10.
} 
Here, (i) is challenging transitivity, and (ii) is challenging antisymmetry and reflexivity. To combat (i), one may appeal to the difference between 'part of' and ' $a$ part of', ${ }^{28}$ such that biological subunits are part of the organ(ism), but not a distinguished part of the organ(ism). And to combat (ii), one may appeal to the relation of proper (rather than improper) parthood as being primitive, which itself is an asymmetric and irreflexive parthood relation between $\mathrm{x}$ and $\mathrm{y}$ where $\mathrm{x} \neq \mathrm{y}$. (Also, "part of' is not synonymous with 'functional subunit of', and so the entailment in (ii) does not follow). Now there may be better examples to demonstrate how biological parthood fails to meet the formal traits of mereology, but there is not space for such an exhaustive account of them here. Yet such an account is not needed anyway, as there is an easier way to preserve the idea that biological parthood is a category of parthood of its own.

Specifically, it could be that there are just more conditions on what it is to be a biological part than a mereological part, so that biological parthood is a special kind of parthood. As such, all biological parts would be mereological parts, but not all mereological parts would be biological parts. Thus, biological parthood would be more restrictive and not fully captured by general mereological parthood. In that case it may turn out that the foetus meets the conditions to be a mereological part of the gestator, but not the extra conditions to be a biological part. So, if the foetus is a biological part of the gestator then it is also a mereological part, yet if the foetus is not a biological part then it may still qualify as being a mereological part. The fact that the foetus and gestator are biological entities is not enough to qualify any parthood relationship between them as biological. The further conditions on biological parts can be cashed out in multiple ways, and I will now address a couple from physiology.

\subsection{Working parts}

According to Gillett's 'Working Parts' account of physiology, an individual y is a part of a whole $z$ when an activity of $y$, together with activities of other parts of $z$, composes or implements an activity of $\mathrm{z}^{29}$ So, do the activities of the foetus compose an activity of the gestator? Gillett has argued that it is hard to find any such shared activity, and that human physiology therefore rejects the Parthood view of pregnancy. ${ }^{30}$ But here we have presupposed the identity of $\mathrm{z}$ in order to question whether $y$ is a part of $z$. If we already take the gestator to exclude the foetus, then any activity of the gestator will not include activities of the foetus. On the other hand, if we already take the gestator to include the foetus, then any activity of the gestator will include activities of the foetus. Thus we cannot look to the activities of $\mathrm{z}$ to see if $\mathrm{y}$ is part of $\mathrm{z}$, as it is the identity of $\mathrm{z}$ that is in question.

\footnotetext{
28 This type of response is described by Sanford (1993) p221.

29 See Gillett (2007).

${ }^{30}$ Gillett (private correspondence and as my commentator at the conference 'The Society for the Metaphysics of Science' at University of Milan in 2018).
} 
The process described above was an example of a top-down approach, to see if $\mathrm{z}$ included y as a part. Instead, let us now try a bottom-up approach in composing the mereological sum of $\mathrm{x}$ and $\mathrm{y}$ and seeing if that entity implements an activity of $\mathrm{z}$. Let us call the mereological sum of $x$ and $y$ simply $x y$. The question is whether $x y$ $=\mathrm{z}$ or a part of $\mathrm{z}$. According to the Working Parts account, we answer this by looking to the activities of $x y$ to see if they compose or implement an activity of $z$. This requires us to see if xy meets conditions for composing an activity, and see if that activity is one of the activities of $\mathrm{z}$. But our problem of presupposing the whole has reappeared. In order to know if the activity of xy is one of $z$ 's we need to have an idea of what z's activities are, which in turn requires an idea of what $z$ is. So even with the bottom-up approach here to ascertain if the foetus is part of the gestator we will presuppose what the gestator is.

\subsection{Immunology}

According to Pradeu's immunological account of physiology, we can identify a biological individual and its parts by seeing what is immunologically tolerated: "any entity [y] which interacts regularly with the immune system and is not eliminated by it is part of the physiological individual [z]." 31 So, is the foetus immunologically tolerated by the gestator? Yes, as after all it is not rejected, and it occupies what Murphy calls an "immunologically privileged site". 32 As such, we can take this immunological account of physiology to support the Parthood view of pregnancy. But again this approach presupposes the identity of the whole in order to ascertain its parts. We have to ask ourselves, whose immune system are we considering? If the immune system in question is the immune system of $\mathrm{z}$, then we have already made an assumption about the identity of the whole $\mathrm{z}$, and whether it includes y or not. If we take $\mathrm{z}$ to include $\mathrm{y}$, the immune system that covers both $\mathrm{z}$ and $\mathrm{y}$ will of course tolerate $z$ and $y$, but if we take $z$ to exclude $y$ then the immune system of $z$ will similarly exclude $y$. Either way, we beg the question in already identifying what $\mathrm{z}$ is. We thus cannot see if $\mathrm{y}$ is part of $\mathrm{z}$ by asking if the whole $\mathrm{z}$ immunologically rejects $\mathrm{y}$.

Again, instead of this top-down approach of looking at the immune system of $z$ to see if it tolerates and interacts with $y$, let us now try a bottom-up approach in composing the mereological sum of $x$ and $y$ and seeing if that entity interacts with and is tolerated by $z$. So, where $x y$ is the foetus (or is partially composed of the foetus) and $z$ is the gestator, does $x y$ interact regularly with the immune system of $z$ ? And is $x y$ tolerated by $z$ ? Is xy equal to part of $z$ ? But yet again, to know the answers to these questions we need to know the identity of $z$. We cannot compare xy with $z$ without knowing what $\mathrm{z}$ is, and we cannot see if $\mathrm{xy}$ interacts with (and is tolerated by) the immune system of $z$ without knowing what that immune system covers. Thus, we again need an idea of the whole $z$ to see if $y$ is a part of it.

31 Pradeu (2016) p805 and see Pradeu (2012).

32 Murphy (2012) p663. 
We have reached a point where we encounter problems whether we use accounts of biological or mereological parts (top-down approaches), or accounts of biological or mereological wholes (bottom-up approaches), to conduct this investigation. So I now make a positive suggestion for how to proceed methodologically.

The philosophy of biology is, of course, distinct from biology. Perhaps, instead of the former, we follow the latter. On this suggestion, I will once again turn to the work of Hawley, who argues that "science can be a guide to metaphysics, but it is not an infallible guide." 33 Of course the sciences may provide some insight, but like Hawley I take it that scientific confirmation is not needed for the meaningfulness or truth of metaphysical claims. ${ }^{34}$ Furthermore if it is metaphysical answers that we require, then scientific theories may not be the easiest place to find them: "there is little prospect of simply 'reading off' a metaphysical picture from current physical science." ${ }^{35}$ Perhaps the scientific theory is incompatible with metaphysical answers, or compatible with many. And if we want the scientific theory to adjudicate between the rivals, then it needs to be a fair and neutral judge. But as Hawley argues, "it is a mistake to think that scientists enter into theory-building without any metaphysical presuppositions whatsoever." 36

I advocate, then, to explore pregnancy as a case of applied metaphysics (à la Hawley), and outline rival models for pregnancy that the humanities together with the sciences can try to adjudicate between, using what I will now describe as a method of reflective equilibrium. Whilst I do not here provide an answer to the debate by applying reflective equilibrium, I rather suggest it as a methodology for the debate moving forward. What follows is a basic introduction to this (generally uncontested) method, showing how and where it should apply.

\section{Reflective equilibrium}

The expanded set of metaphysical possibilities and sources of evidence presented so far show that neither metaphysics in general or of pregnancy in particular is sufficient on its own to determine our view of the other. As a result, we have to consider how to handle their dialectical interaction during the course of philosophical inquiry. ${ }^{37}$ Furthermore, investigating the methodological issues that come up in the metaphysics of pregnancy can be illuminating for how we approach the practice of philosophy in general and what we think the aims of philosophy are. Namely, are we doing descriptive or prescriptive work? Are we attempting to describe what we already take pregnancy to be, or are we attempting to prescribe how we ought to understand pregnancy? We are also led to question the nature of counterexamples - ought we to hold

\footnotetext{
33 Hawley (2006) p468.

34 Ibid. p453.

35 Hawley (2018) p2. I have also argued for this elsewhere (Finn, 2017).

36 Ibid. See also Hawley (2006) p4: "Isn't it naive to assume that scientists investigate the world without metaphysical prejudice, so that their findings can act as unbiased arbiters between rivals?" I speculate that yes, it is naïve.

37 Thanks to an anonymous reviewer for putting the point in this way for me.
} 
fast onto examples from the world (like pregnancy) and produce a theory based on them, or ought we to hold fast onto our theories (like maximality) and learn about the world as a result of them? Until we have set the meta-philosophical agenda we cannot draw conclusions about pregnancy, as until we have decided on our aims and methods, we cannot expect to get good results.

Focusing on this real-life example of pregnancy, rather than fantastical examples like brain surgery and teletransportation that we see elsewhere in the metaphysics literature, could provide real evidence for the adequacy of metaphysical theories, as if they couldn't accommodate for pregnancy then they ought to be rejected. This was the direction of entailment that Kingma suggested by taking pregnancy seriously on its own terms and rejecting maximality. But alternatively, we learn about complex processes like pregnancy through theory. If we found that our best theory entailed that the Containment view was wrong, for example, then all the worse for the Containment view. This was the direction that Kingma practised by importing theory from the philosophy of biology to motivate her Parthood view.

If pregnancy can be used as a counterexample to a theory, then that theory must be wrong, unless we of course have misunderstood the metaphysics of pregnancy itself in the first place. And so our best theories must help to provide insight into the metaphysics of pregnancy as well. Therefore, going back to our theories with this example of pregnancy in hand will not only teach us about pregnancy but will help us to determine our better theories in light of this example. Pregnancy can thus provide evidence for or against a theory, and theories can constrain what we say of pregnancy. So whatever we say about pregnancy it will be metaphysically informed, and whatever metaphysics we hold will be able to accommodate pregnancy.

This type of methodology on adjusting your position in both directions is called 'Reflective Equilibrium', described as such:

As a procedure, reflective equilibrium is simply a familiar kind of standard scientific method with a new name. A theory is constructed to account for a set of observations. Recalcitrant data may be rejected as noise or explained away as the effects of interference of some sort. Recalcitrant data that cannot be plausibly dismissed force emendations in theory. What counts as a plausible dismissal depends, among other things, on the going theory, as well as on background theory and on knowledge that may be relevant to understanding the experimental design that is generating observations, including knowledge of the apparatus and observation conditions. This sort of mutual adjustment between theory and data is familiar feature of scientific practice. ${ }^{38}$

So, what I am advocating is that we utilise this style of mutual adjustment when it comes to theorising about pregnancy. Sometimes a theory will tell us about pregnancy, and force change in our understanding of pregnancy. Yet we note that our theories are not completely adequate without being built using the data that pregnancy provides. And so sometimes pregnancy will provide recalcitrant data that forces change in our theories. Yet whether pregnancy provides recalcitrant data requires

38 Cummins (1999) p113. 
us to figure out what we think of pregnancy, as our understanding of pregnancy is not completely adequate either. The upshot is, as we go back and forth in both directions in this process of mutual adjustment we aim to rid of bias and presuppositions, arriving at better, fairer, results that are hopefully closer to truth.

Thinking ahead, the problems that I foresee in utilising this method of reflective equilibrium (not just in the case of pregnancy, but in all cases), will be the significant use of intuitions. We will need to decide when to adjust in which direction based on our intuitions. We will need to decide when something counts as a counterexample based on our intuitions. Intuitions, essentially, will need to play the role that observation plays when utilising reflective equilibrium in scientific theorising. Now of course the use of intuitions in philosophical theorising has already received much attention which I do not aim to recount here. ${ }^{39}$ But what I will add is the particular problems that such use of intuitions will have in the case of pregnancy. Not only may our intuitions be misleading when they are corrupted by many influencing factors (including what the dominant view might be), but also, as Kingma, notes:

It is worth considering who has this intuition, who does not, and whether everyone is in an equal position to have their intuitions on these matters regarded as knowledgable or reliable. Women, in particular pregnant women and mothers, have hardly had a dominant voice in social, medical or philosophical discussions of pregnancy. ${ }^{40}$

Though there have been specific reflections on the role of women's intuitions and phenomenological experience of pregnancy, yet unsurprisingly they may not always converge. In many places, however, we see the foetus described in such a way as being both a part of and contained by the gestator:

Women carry foetuses in their bodies, it is true. It is equally true that foetuses are part of women's bodies. ${ }^{41}$

The foetus is both inside and of the pregnant woman's body, so that the distinctions between 'inner' and 'outer' are elided. ${ }^{42}$

[In pregnancy] I experience my insides as the space of another, yet [part of] my own body. ${ }^{43}$

Notice that such pictures of pregnancy do not neatly fit into the more exclusive binary presented by Kingma as the foetus being either a part of or (merely) contained by the gestator. One could reinterpret these quotes as making use of a notion of containment that is compatible with parthood, such that no contradiction would arise in holding $\mathrm{x}$ to be a part of $\mathrm{y}$ and $\mathrm{y}$ containing $\mathrm{x}$. Yet perhaps a contradiction is precisely what these quotes aim for, demonstrating the paradox of pregnant

\footnotetext{
39 See Pust (2017) for an overview.

40 Kingma (2019) p638.

41 Purdy (1990) p273. Purdy goes on to state that "[Many] would argue that these claims are inconsistent", as I would if the 'carrying' excludes parthood.

42 Lupton (2009) p78.

43 Young (2005) p49.
} 
embodiment. Though not all testimonies conform to this, as Kingma ${ }^{44}$ notes, they range from messy and ambiguous, to active and agential, to constructed and transitional and beyond.

Therefore, the suggestion to endorse the method of reflective equilibrium comes with caution, and a note that it may not answer all of our problems. But it may be the least dogmatic and most intellectually honest way to proceed, and given the current state of the debates, I argue that reflective equilibrium be consciously applied from the very beginning. My take-home message then is that we ought to rethink pregnancy in light of theories, as well as rethinking theories in light of pregnancy, without presuming that we have enough unbiased evidence to do either of those directions alone (because we simply do not!).

\section{Why it matters}

As for why all of this matters, given that Kingma poses the question as 'Were you a part of your mother?' in her Mind article, one of the implications may be that we learn what we once were - namely, a part of our mothers or not. This has intrinsic value, as truth is valuable. It also has instrumental value, as it may be that there are ethical consequences of such metaphysical views (though these are not straightforward).

I take it that given the complexity of the debates in reproductive ethics (such as abortion, surrogacy, medicalisation of birth, etc.), the metaphysical models will not on their own be sufficient to determine the legitimacy or illegitimacy of any particular problematic case, since the models alone do not determine, for example, the rights that a gestator has over their body or the produce of their body, nor the moral status of the foetus or what sort of thing the foetus is. However, many of the reasons that we cite to support our stance on reproductive issues are based (sometimes unknowingly) on metaphysical grounds (though admittedly the grounds are not so much regarding the relationship between foetus and gestator, but more commonly regarding what sort of thing the foetus is). As such, it is important to look carefully at these metaphysical grounds if they are to be used as motivation for or against a reproductive ethical issue, and challenge any metaphysical assumptions that may have been made. As Kingma notes:

The parthood view may also prompt a reconsideration of various ethical and legal questions, particularly where work in these domains has presupposed a containment view of pregnancy. For example, those who discuss or invoke certain moral and legal rights and principles... typically assume that the parties involved have separate bodies. So how, if at all, are these to be understood when it comes to a situation in which one body is a part of another? This is an open question, but one which must, in light of the parthood view, be settled by

\footnotetext{
44 See Kingma (2019); Young (2005); Kristeva (1980); Irigaray (1985); Howes (2007); Ruddick (1989); Nelson (1994); Bergum (1997); and Martínez-Quintero and De Jaegher (2020).
} 
any who want to invoke such rights or principles in ethical and legal debates that concern pregnancy. ${ }^{45}$

Such domains that seem to have presupposed a containment view of pregnancy include surrogacy and ectogenesis. I (and others) have discussed these elsewhere. ${ }^{46}$ There are other areas of reproductive ethics where the metaphysics of pregnancy can have impact - I leave that for future work and for the readers to ponder on. For now, it suffices to say that the metaphysics of pregnancy matters. But does the specific methodology matter?

It is important to engage in meta-philosophical, methodological enquiry, especially when it comes to pregnancy, since areas of mainstream analytic philosophy like metaphysics are fairly new to these issues - and it is my hypothesis that the origins of metaphysics (or philosophy more generally) could be partially explanatory. As sociologist Barbara Katz Rothman describes:

Philosophy has strong roots in a patriarchal society, a world in which men's bodies are the taken-for-granted ordinary, and women's an interesting variation; a world in which the children of men grow in the bodies of women, where the seed of Abraham covers the world. ${ }^{47}$

A feminist, woman-centered (or rather human not man-centered) world of philosophy is still only in its early stages of the making, and philosophy still has a lot further to go in order to come to terms with its history and assumptions. And so whilst reflective equilibrium may arguably already be in place, it is operating within systems that were not held accountable to their histories. In a sense, then, we must go back to the start.

Whilst philosophy as a research area or theoretical endeavor does not necessarily set out to make the social world better, our work does have its consequences. Specifically, our conclusions about what a pregnancy is can have significant impact. Ideas about pregnancy grew out of the positions of men of privilege, and those men used their analyses to justify those positions - a never-ending, and vicious, echochamber. But when women, people with different understandings of pregnancy as a state and possibility, enter the dialogue, the analysis of pregnancy likely shifts. And then the consequences of that analysis will reinforce that shift. The same goes for the inclusion of trans-perspectives in this gendered area. So perhaps what is needed when tackling methodology (not just in the metaphysics of pregnancy) is a study of the sociology of philosophy (and the philosophy of sociology!) to offer new things to the discussion. ${ }^{48}$

\footnotetext{
45 Kingma (2019) p640. Furthermore, in prompting reconsideration of ethical matters, one might incorporate them as socio-political aims in investigating pregnancy, relevant in the reflective equilibrium. See e.g. Brigandt (2020).

46 See Finn (2018), Finn and Isaac (forthcoming), and Kingma and Finn (2020).

47 In private correspondence. But for more on this idea, see Rothman (1982).

48 There is such a huge wealth of literature on women in philosophy within the history of philosophy and feminist epistemology in particular, that I direct the reader to the following general resources and edited collections to find out more: Anderson (2020); Witt and Shapiro (2021); Hutton (2019); O'Neill and Lascano (2019); Buxton and Whiting (2020); and Finn (2021).
} 


\section{Conclusion}

This paper has gone through many meta-philosophical issues to highlight the difficulties that the project of researching the metaphysics of pregnancy faces. I started by outlining answers to whether the foetus is a part of the gestator. Then I embarked on the methodological investigation as to how to go about adjudicating between them in metaphysics and the philosophy of biology. I demonstrated the problems and unanswered questions that the project encounters, using both top-down and bottom-up approaches which presuppose the identity of the whole in order to identify its parts. Finally, I suggested that we adopt a method of reflective equilibrium for future purposes. ${ }^{49}$

Acknowledgements Special thanks go to Elselijn Kingma, Barbara Katz Rothman, Achille Varzi, and Laura Franklin-Hall for their helpful comments and input on this paper. I am grateful to the members of the project 'Better Understanding the Metaphysics of Pregnancy' at the University of Southampton for discussion of these topics and earlier drafts. I also thank the audience of the 'Logic and Metaphysics Workshop' in New York and the department at the University of Leeds for their feedback where I presented earlier versions of this paper. This paper is part of a project that has received funding from the European Research Council (ERC) under the European Union's Horizon 2020 research and innovation program, under grant agreement number 679586

Funding European Research Council (ERC) under the European Union's Horizon 2020 research and innovation program, under grant agreement number 679586.

\section{Declarations}

Conflict of interest No conflict of interest.

Open Access This article is licensed under a Creative Commons Attribution 4.0 International License, which permits use, sharing, adaptation, distribution and reproduction in any medium or format, as long as you give appropriate credit to the original author(s) and the source, provide a link to the Creative Commons licence, and indicate if changes were made. The images or other third party material in this article are included in the article's Creative Commons licence, unless indicated otherwise in a credit line to the material. If material is not included in the article's Creative Commons licence and your intended use is not permitted by statutory regulation or exceeds the permitted use, you will need to obtain permission directly from the copyright holder. To view a copy of this licence, visit http://creativecommons.org/ licenses/by/4.0/.

\footnotetext{
${ }_{49}$ Special thanks go to Elselijn Kingma, Barbara Katz Rothman, Achille Varzi, and Laura Franklin-Hall for their helpful comments and input on this paper. I am grateful to the members of the project 'Better Understanding the Metaphysics of Pregnancy' at the University of Southampton for discussion of these topics and earlier drafts. I also thank the audience of the 'Logic and Metaphysics Workshop' in New York and the department at the University of Leeds for their feedback where I presented earlier versions of this paper. This paper is part of a project that has received funding from the European Research Council (ERC) under the European Union's Horizon 2020 research and innovation program, under grant agreement number 679586 .
} 


\section{References}

Anderson, E. (2020). 'Feminist Epistemology and Philosophy of Science', The Stanford Encyclopedia of Philosophy, Zalta, E. N. (ed.), https://plato.stanford.edu/archives/spr2020/entries/feminism-epistemology/ (accessed April 2021)

Azzouni, J. (2004). Theory, Observation, and Scientific Realism. British Journal for the Philosophy of Science, 55(3), 371-92.

Bergum V. (1997). A Child on Her Mind: The Experience of Becoming a Mother, Westport, Conn.: Bergin \& Garvey.

Brigandt, I. (2020). How to philosophically tackle kinds without talking about 'natural kinds.' Canadian Journal of Philosophy. https://doi.org/10.1017/can.2020.29

Buxton, R. \& Whiting, L. (2020). Philosopher Queens, Unbound.

Cummins, R. (1999). 'Reflections on Reflective Equilibrium', from Ramsey, W. and DePaul, M. (eds.) The Role of Intuition in Philosophy. New York: Rowman \& Littlefield.

DiFrisco, J. \& Mossio, M. (2020). 'Diachronic Identity in Complex Life Cycles: An Organizational Perspective', from Meincke, A. S. and Dupré, J. (eds.) Biological Identity: Perspectives from Metaphysics and the Philosophy of Biology. Routledge: 177-199.

Feyerabend, P. K. (1959). An Attempt at a Realistic Interpretation of Expeience. Realism, Rationalism, and Scientific Method (Philosophical Papers I) (pp. 17-36). Cambridge University Press.

Finn, S. (2017). The Role of Existential Quantification in Scientific Realism. Philosophy, 92(361), $351-367$.

Finn, S. (2018). The Metaphysics of Surrogacy. In D. Boonin (Ed.), The Palgrave Handbook of Philosophy and Public Policy (pp. 649-659). Springer International Publishing AG.

Finn, S. (2021) (ed.) Women of Ideas, Oxford University Press.

Finn, S. (forthcoming). 'The Mereotopology of Pregnancy', Journal of Medicine and Philosophy.

Finn, S. \& Isaac, S. (forthcoming). 'Evaluating Ectogenesis via the Metaphysics of Pregnancy', DavisFloyd, R. (ed.) Social Science Perspectives on Birth and Reproduction, Routledge

Gillett, C. (2007). 'Hyper-Extending the Mind? Setting Boundaries in the Special Sciences' Philosophical Topics, 351, 161-188.

Grose, J. (2020). How Many Organisms during a Pregnancy? Philosophy of Science, 87, 5.

Hacking, I. (1983). Representing and Intervening: Introductory Topics in the Philosophy of Natural Science. Cambridge University Press.

Hawley, K. (2006). Science as a guide to metaphysics? Synthese, 149(3), 451-470.

Hawley, K. (2016). 'Applied Metaphysics', in Lippert-Rasmussen, K., Brownlee, K. and Coady, D. (eds.), A Companion to Applied Philosophy, Blackwell: 165-179.

Hawley, K. (2018). 'Social Science as a Guide to Social Metaphysics?', Journal for General Philosophy of Science.

Howes, M. (2007). Maternal Agency and the Immunological Paradox of Pregnancy. In H. Kincaid \& J. McKitric (Eds.), Establishing Medical Reality: Essays in the Metaphysics and Epistemology of Biomedical Science (pp. 179-198). Springer.

Howes, M. (2008) 'Conceptualizing the maternal-fetal relationship in reproductive immunology', from Kroker, K., Keelan, J., and Mazumdar, P. M. H. (eds.) Crafting immunity: Working histories of clinical immunology. Aldershot, UK: Ashgate.

Hutton, S. (2019). Women, Philosophy and the History of Philosophy. British Journal for the History of Philosophy, 27(4), 684-701.

Irigaray, L. (1985). This Sex Which Is Not One, Ithaca: Cornell.

Kaiser, M. (2018). 'Individuating Part-Whole Relations in the Biological World', to appear in Bueno, O., Chen, R. L., and Fagan, M. B. , 2018 Kaiser, M. (2018) 'Individuating Part-Whole Relations in the Biological World', to appear in Bueno, O., Chen, R. L., and Fagan, M. B. (eds.) (2018): Individuation, Process and Scientific Practices, Oxford University Press.

Kingma, E. (2018). Lady Parts: The Metaphysics of Pregnancy. Royal Institute of Philosophy Supplement, $82,165-187$.

Kingma, E. (2019). 'Were you part of your mother? The Metaphysics of Pregnancy', Mind, 128(511), 609-646.

Kingma, E., \& Finn, S. (2020). 'Neonatal Incubator or Artificial Womb? Distinguishing ectogestation and ectogenesis using the metaphysics of pregnancy', Bioethics, 34(4), 354-363. 
Kristeva, J. (1980). Desire in Language: A Semiotic Approach to Literature and Art, ed. L. S. Roudiez, trans. T. Gora, A. Jardine \& L. S. Soudiez, NY: Columbia University Press

Kuhn, T. (1977). 'Objectivity, Value Judgment and Theory Choice', in The Essential Tension. University of Chicago Press.

Lupton, D. (2009). 'Risk and the Ontology of Pregnant Embodiment', in her Risk \& Social-Cultural Theory: New Directions and Perspectives. Cambridge University Press.

Martínez-Quintero, A., \& De Jaegher, H. (2020). Pregnant Agencies: Movement and Participation in MaternalFetal Interactions. Frontiers in Psychology, 11, 14.

Mitchell, S. (1997). Pragmatic laws. Philosophy of Science, 64, 4.

Murphy, K. (2012). Janeway's Immunobiology (8th ed.). Garland Science.

Nelson, L. H. (1994). The Architect and the Bee: Some Reflections on Postmortem Pregnancy. Bioethics, 8, 247-67.

Nuño de la Rosa, L. (2010). Becoming organisms: the organisation of development and the development of organisation. History and Philosophy of the Life Sciences, 32, 289-315.

Nuño de la Rosa, L., Pavlicev, M., \& Etxeberria, A. (2021). Pregnant females as historical individuals: an insight from the philosophy of evo-devo. Frontiers in Psychology, 11, 37-41.

O’Neill, O., \& Lascano, M. P. (2019) (eds.) Feminist History of Philosophy: The Recovery and Evaluation of Women's Philosophical Thought, Springer International

Popper, K. R. (1959). The Logic of Scientific Discovery. Basic Books.

Pradeu, T. (2012). The limits of the self: immunology and biological identity. Oxford University Press.

Pradeu, T. (2016). The many faces of biological individuality. Biology and Philosophy, 31, 761-773.

Psillos, S. (1999). Scientific Realism: How Science Tracks Truth. Routledge

Purdy, L. (1990). Are Pregnant Women Fetal Containers? Bioethics, 4(4), 273-291.

Pust, J. (2017). 'Intuition', The Stanford Encyclopedia of Philosophy, Edward N. Zalta (ed.). https://plato. stanford.edu/archives/sum2017/entries/intuition/

Rescher, N. (1955). Axioms for the Part Relation. Philosophical Studies, 6, 8-11.

Rothman, B. K. (1982). In Labor: Women and Power in the Birthplace, W W Norton \& Co Inc.

Ruddick, S. (1989). Maternal Thinking: Toward a Politics of Peace. Beacon Press.

Sanford, D. (1993). The problem of the many, many composition questions, and naive mereology. Noûs, 27, 219-228.

Sider, T. (2001). Maximality and Intrinsic Properties. Philosophy and Phenomenological Research, 63, 357-364.

Smith, B., \& Brogaard, B. (2003). Sixteen Days. Journal of Medicine and Philosophy, 28, 45-78.

Soto, C. (2015). The current state of the metaphysics of science debate. Philosophica, 90, 23-60.

Triviño, V., \& Suárez, J. (2020). 'Holobionts: Ecological communities, hybrids, or biological individuals? A metaphysical perspective on multispecies systems', Studies in History and Philosophy of of Science Part C: Biological and Biomedical Sciences: 1-11.

van Fraassen, B. (1980). The Scientific Image. The Clarendon Press.

Witt, C., \& Shapiro, L. (2021). 'Feminist History of Philosophy', The Stanford Encyclopedia of Philosophy, Zalta, E. N. (ed.), https://plato.stanford.edu/archives/spr2021/entries/feminism-femhist/ (accessed April 2021)

Woodward, J. (2003). Making Things Happen: A Theory of Causal Explanation. Oxford University Press.

Young, I. M. (2005). On Female Body Experience: 'Throwing Like A Girl' and other essays. Oxford University Press.

Publisher's Note Springer Nature remains neutral with regard to jurisdictional claims in published maps and institutional affiliations. 